\title{
THE CONVERSION RATE OF ARTHROSCOPY TO TOTAL JOINT ARTHROPLASTY IN PATIENTS WITH KNEE OSTEOARTHRITIS
}

\author{
LORAND VITALIS ${ }^{1}$, SANDOR ZUH ${ }^{2}$, OCTAV RUSSU ${ }^{3}$, TUDOR SORIN POP \\ ${ }^{1,2,3,4}$ Mureș Clinical County Hospital, ${ }^{2,3,4}$ "George Emil Palade" University of Medicine, Pharmacy, Science, and Technology of Târgu Mureș
}

\begin{abstract}
Keywords: osteoarthritis, knee arthroscopy, meniscal tears, total knee arthroplasty

Abstract: The efficacy of knee arthroscopy in the treatment of osteoarthritis has been questioned during the last years by many studies, which demonstrated its lack of effect. The aim of our review was to summarize recent data published in the scientific literature upon the conversion rate from arthroscopy to total arthroplasty in patients with knee osteoarthritis. We conducted a search of scientific articles discussing the association between arthroscopy and total knee arthroplasty in patients with osteoarthritis, using PubMed/Medline databases. The following parameters were evaluated: age and gender distribution of the patients, indications for arthroscopy, conversion to arthroplasty, time interval between the two procedures. We concluded that the current literature underlines the poor efficacy of arthroscopy for degenerative meniscus and cartilaginous pathology. The high rate of progression to knee arthroplasty, especially among older patients with comorbidities should determine specialists to evaluate the risks and benefits associated with arthroscopic surgery in these cases.
\end{abstract}

\section{INTRODUCTION}

Knee osteoarthritis is a debilitating disease, affecting $10 \%$ of the overall population; among these patients, $35 \%$ have symptoms like pain and loss of knee joint function, while about $90 \%$ have meniscal tears, documented on magnetic resonance imaging.(1) For the structural progression associated with osteoarthritis $(\mathrm{OA})$ there is no available treatment, therefore in the early stages the symptoms are managed with conservative therapies, such as nonsteroidal anti-inflammatory drugs and physical therapy. The surgical treatments, represented mainly by arthroscopy and total knee arthroplasty (TKA), are indicated in cases with progressive pain and disability.(2) The most important factors influencing the decision for surgery are the clinical criteria (mostly the level of pain) and radiographic severity.(3) In cases with pain and moderate radiographic changes, the decision to indicate knee arthroplasty (KA) is more difficult as $90 \%$ of these patients have meniscal damage. For the patients with less severe OA, a widely used procedure is still the arthroscopic meniscectomy, although it is controversial regarding the effectiveness as many studies reported no benefit in comparison with sham surgery, or physical therapy while others showed important benefits, especially in "older patients", but without a clear age cut-off defined in the literature. One of the main concerns in providing arthroscopic surgery for these patients is the risk of conversion to KA that has been described in a recent systematic review to be $2.62 \%$ per year.(2) A frequent observation was that patients with osteoarthritis treated by arthroscopy progressed to TKA; Dervin et al (4) considered that up to $20 \%$ of patients undergo TKA within one year of arthroscopy, while Koyonos et al (5) reported rates under 5\%. Therefore, improved knowledge of the risk for TKA following arthroscopy and the time interval between these interventions could help specialists to better advice patients regarding the best treatment option and also enhance a better resource allocation from national health programs for osteoarthritis.

\section{AIM}

The aim of our review is to summarize recent data published in the scientific literature upon the conversion rate from arthroscopy to total arthroplasty in patients with knee osteoarthritis.

\section{MATERIALS AND METHODS}

We conducted a search of scientific articles published in the time span 2002-2020, discussing the association between arthroscopy and TKA in patients with OA, using PubMed/Medline databases (figure no. 1) As key words we used: osteoarthritis, arthroscopy, meniscal tears, total knee arthroplasty. The inclusion criteria for studies were: longitudinal design, investigation of the rate of TKA after arthroscopic knee surgery in patients with knee OA. The exclusion criteria for studies were: the examination of only one of these surgical procedures, with no assessment of any risk for conversion, patients with a mean age < 40 years, the use of arthroscopy as part of a knee osteotomy and arthroscopic management of fractures or patellar instability. From a total of 218 articles, we selected 33 original and review articles. We selected the following parameters: age and gender distribution of the patients in the reviewed studies, indications for arthroscopic surgery, conversion to TKA, time interval between arthroscopy and TKA, age of the patients undergoing conversion.

ARTHROSCOPY AND DEGENERATIVE

\section{MENISCAL TEARS}

Scientific data regarding the treatment of degenerative meniscal tears reported that the indication of arthroscopic surgery is not supported and non-operative management should

${ }^{1}$ Corresponding author: Sandor Zuh, Str. Mihai Viteazu, Nr. 31, Târgu Mureș, Romania, E-mail: zuh.sandor@gmail.com, Phone: +40745 426183 Article received on 22.02.2021 and accepted for publication on 31.05.2021 


\section{CLINICAL ASPECTS}

be the first treatment option.(6,7) Despite mounting evidence questioning its efficacy, knee arthroscopy remains a frequent practice for patients with degenerative meniscal tears.(8-11) These lesions are caused by chronic degenerative processes, may be preceded by trauma and are mainly seen in older patients, with associated knee OA.(12,13) The National Institute for Health and Care Excellence in United States indicated no referring for arthroscopic lavage and debridement for the treatment for OA, except for patients with knee OA and a clear history of mechanical locking. Despite this recommendation, arthroscopic knee surgery with meniscectomy and/or debridement remains a well-established procedure for the treatment of degenerative meniscal tears. $(14,15)$

Those who insist on indicating this surgical procedure argue that the symptoms such as locking, clicking or acute joint line tenderness come from the degenerative meniscus and are determined by mechanical factors. However, the sensitivity and specificity of these symptoms attributed to the degenerative meniscus in the knees with OA are considered to be low and moreover, asymptomatic meniscal tears are highly prevalent in patients with knee OA. $(13,17)$ These factors make it difficult to determine whether the symptoms are induced by the meniscal tear or by other factors such as synovitis and cartilage damage.(12) There is not enough scientific support to certify that meniscectomy relieves knee catching or locking and therefore, the benefits but also the related risks (thrombosis, infection) of the surgical intervention must be carefully evaluated.(18)

Figure no. 1. Flow diagram showing the search and selection process of the reviewed articles

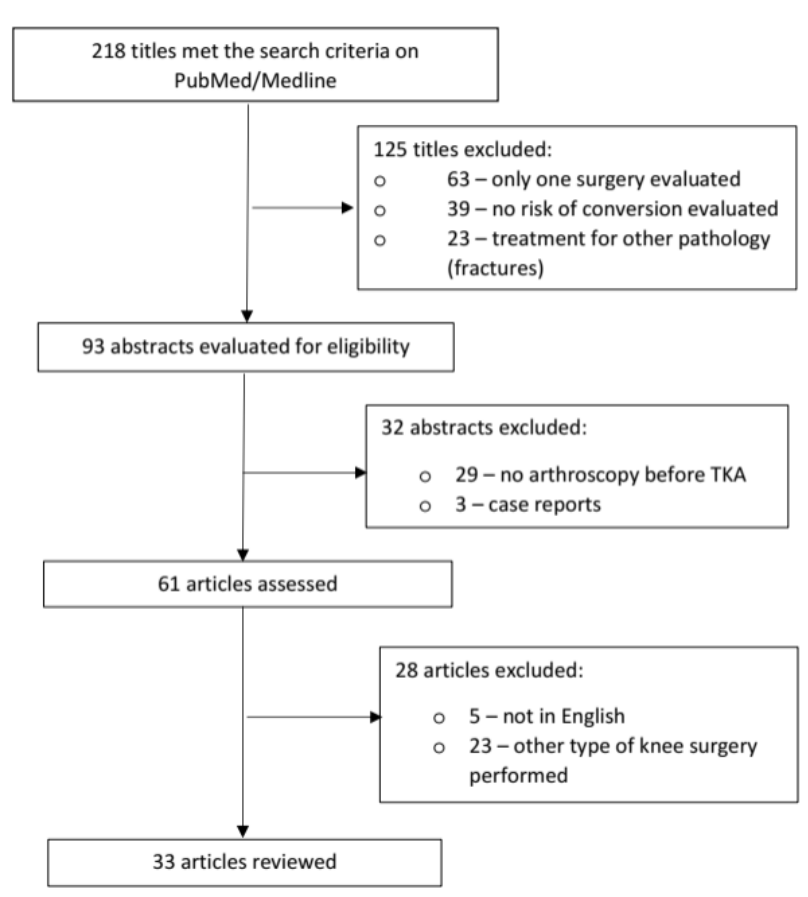

Moreover, it was reported that after arthroscopic meniscectomy, patients may have a higher risk of worsening cartilage damage and for developing late onset OA.(19) However, the impact of arthroscopy on the progression of an already diagnosed knee $\mathrm{OA}$ is not clear yet. The general consensus is that degenerative meniscal tears, without symptoms of locking and catching, can be successfully treated by exercise therapy as a first line treatment since arthroscopic surgery is not able to provide better outcomes up to middle term evaluation. Surgical approach might be considered in case of poor response after conservative treatment and the patient should be anyway informed about the early and delayed risks linked to surgery and meniscal resection, especially in case of concurrent presence of cartilage damage.

\section{CONVERSION OF ARTHROSCOPY TO TKA}

Recent published data reported that for patients with symptomatic knee OA, arthroscopy with meniscectomy was associated with a 3-fold increase in the risk for $\mathrm{KA}$, as a consequence of a possible increased OA progression. (2) This might be caused by the removal of the meniscus with its cartilage protecting effect, in a knee with osteoarthritic changes. More data to confirm the negative influence of meniscectomy on the progression of OA can only come from long term follow up randomized controlled studies, expected to be released in a few years from now. For the time being, patients and specialists should be aware of the higher risk for knee replacement surgery after arthroscopic meniscectomy and weigh carefully all the possible negative consequences before choosing any treatment.(19-21) Several studies, based on the information provided by the Osteoarthritis Initiative (OAI) cohort, have tried to identify the factors that could predict the conversion to KA after arthroscopic surgery (table no. 1).(22)

Table no. 1. Risk factors influencing the conversion of arthroscopy to knee arthroplasty

\begin{tabular}{|c|c|c|}
\hline Authors & Year & Conversion risk factor \\
\hline Eckstein et al & 2013 & Loss of cartilage from central tibia \\
\hline Jameson et al & 2014 & Female gender, increasing age \\
\hline Zikria et al & 2016 & $\begin{array}{c}\text { High Kellgren-Lawrence score } \\
\text { Female gender } \\
\text { More clinical and radiological signs } \\
\text { The wear of the lateral tibial plateau }\end{array}$ \\
\hline Boyd et al & 2016 & $\begin{array}{c}\text { Obesity, rheumatoid arthritis, } \\
\text { depressive disorders, diabetes, } \\
\text { increasing age (> 70) }\end{array}$ \\
\hline Winter et al & 2017 & Age, OA severity \\
\hline Agarwalla et al & 2020 & Obesity, depression \\
\hline Klasan et al & 2020 & $\begin{array}{c}\text { Higher ICRS grade of the lateral tibial } \\
\text { plateau and age (equally consistent) }\end{array}$ \\
\hline
\end{tabular}

The OAI uses only magnetic resonance imaging (MRI) which is considered the best investigation method for the assessment of cartilage changes.(23) Data from the OAI cohort was analysed by Eckstein et al. (24) in order to identify which subregion is the strongest prognostic factor for conversion to TKA. The authors concluded that this factor is represented by the loss of cartilage thickness from the central tibia; furthermore, this parameter can be assessed in longitudinal studies. Zikria et al. (25) considered that in patients who had been subjected to arthroscopy in the past, the female patients, higher Kellgren-Lawrence scores and more clinical symptoms were parameters associated with an increased risk for conversion to KA. In the evaluation of meniscal and chondral damage, direct assessment during arthroscopy has a high positive correlation with histological examination and therefore is considered superior to MRI.(26) Until now, we could find no study evaluating the status of the cartilage based on arthroscopic observations, in order to find risk factors that could indicate the progression to KA. Klasan et al. (27) considered that besides age, the only significant anatomical parameter that predicted the conversion to joint replacement surgery was a higher ICRS (International Cartilage Regeneration and Joint Preservation Society) grade of the lateral tibial plateau at arthroscopy. From the investigated demographic variables, age was unsurprisingly shown to be equally consistent in its predictive value.

In the last 20 years, the indication of arthroscopy for older patients with knee symptoms raised intense debates in the literature; some may benefit from non-surgical treatment, while others have no improvement after surgery or their symptoms 


\section{CLINICAL ASPECTS}

become worse.(28) The comparison between arthroscopic lavage of the knee and physical therapy showed no clinical benefit of the arthroscopy. $(29,30)$ Siemieniuk et al. (28) considered that in older patients the risk of conversion to KA is much higher, the arthroscopy in these cases is not necessary as it predisposes to increasing patient morbidity and adding to the cost burden for the health care system. Recent published data reported that after 2 to 5 years the conversion rates were $14 \%$ to $17 \%$ respectively, associated with risk factors as obesity, female gender and age over 60 years. $(31,32)$ The conversion rate was even higher (62\% at 4,4 years) in series study on 81 knees after arthroscopy with Kellgren-Lawrence scores of 3 and 4 knee OA, in a group of patients with a mean age of 58 years old.(33) These findings should be shared with patients when clinicians discuss the advantages and drawbacks of arthroscopy.

\section{CONCLUSIONS}

The current literature highlights the poor efficacy of arthroscopy for degenerative meniscus and cartilaginous pathology, suggesting a high progression rate to TKA especially among older patients. The general opinion is that for degenerative meniscal tears, without symptoms of locking and catching, the first line of treatment is represented by exercise therapy as arthroscopic surgery is unable to offer better outcomes on middle term follow-up. Surgery might be considered when there is a poor response after conservative treatment; anyway, the patient should be informed of the early and delayed risks linked to surgery and meniscal resection, especially in case of concurrent presence of cartilage damage. Therefore, clinicians and patients considering knee arthroscopy should discuss the likelihood of subsequent TKA and they should weigh both the risks and benefits of surgery.

\section{REFERENCES}

1. Deshpande BR, Katz JN, Solomon DH, Yelin EH, Hunter DJ, Messier SP,et al. Number of persons with symptomatic knee osteoarthritis in the US: impact of race and ethnicity, age, sex, and obesity. Arthritis Care Res. 2016;68(12):1743-50.

2. Winter AR, Collins JE, Katz JN. The likelihood of total knee arthroplasty following arthroscopic surgery for osteoarthritis: a systematic review. BMC Musculoskeletal Disord. 2017;18:408.

3. Huynh C, Puyraimond-Zemmour D, Maillefert JF, Conaghan PG, Davis AM, Gunther K-P, et al.- Factors associated with the orthopaedic surgeon's decision to recommend total joint replacement in hip and knee osteoarthritis: an international cross-sectional study of 1905 patients. Osteoarthr Cartil. 2018; 26:1311-8.

4. Dervin GF, Stiell IG, Rody K, Grabowski J. Effect of arthroscopic debridement for osteoarthritis of the knee on health-related quality of life. J Bone Joint Surg Am. 2003;85-A(1):10-9.

5. Koyonos L, Yanke AB, McNickle AG, Kirk SS, Kang RW, Lewis PB, Cole BJ. A randomized, prospective, doubleblind study to investigate the effectiveness of adding DepoMedrol to a local anesthetic injection in postmeniscectomy patients with osteoarthritis of the knee. Am J Sports Med. 2009;37(6):1077-82.

6. Thorlund JB, Juhl CB, Roos EM, Lohmander LS Arthroscopic surgery for degenerative knee: systematic review and meta-analysis of benefits and harms. BMJ 2015;350:2747.

7. Khan M, Evaniew N, Bedi A, Ayeni OR, Bhandari M. Arthroscopic surgery for degenerative tears of the meniscus: a systematic review and meta-analysis. CMAJ. 2014;186:1057-64.
8. Jarvinen TL, Sihvonen R, Englund M. Arthroscopy for degenerative knee - a difficult habit to break? Acta Orthop. 2014;85:215-7.

9. Lubowitz JH, Provencher MT, Rossi MJ. Could the New England Journal of Medicine be biased against arthroscopic knee surgery? Part 2. Arthroscopy. 2014;30:654-5.

10. Rossi MJ, D'Agostino RB, Jr., Provencher MT, Lubowitz JH. Could the New England journal of medicine be biased against arthroscopic knee surgery? Arthroscopy. 2014;30:536-7.

11. Price A, Beard D. Arthroscopy for degenerate meniscal tears of the knee. BMJ. 2014;348:g2382.

12. Buchbinder R, Harris IA, Sprowson A. Management of degenerative meniscal tears and the role of surgery. BMJ. 2015;350:h2212.

13. Englund M, Roemer FW, Hayashi D, Crema MD, Guermazi A. Meniscus pathology, osteoarthritis and the treatment controversy. Nat Rev Rheumatol. 2012;8:412-9.

14. Rongen JJ, Rovers MM, van Tienen TG, Buma P, Hannink $\mathrm{G}$, Increased risk for knee replacement surgery after arthroscopic surgery for degenerative meniscal tears: a multi-center longitudinal observational study using data from the osteoarthritis initiative, Osteoarthritis and Cartilage 2016, doi: 10.1016/j.joca.2016.09.013.

15. Abrams GD, Frank RM, Gupta AK, Harris JD, McCormick FM, Cole BJ. Trends in Meniscus Repair and Meniscectomy in the United States, 2005-2011. Am J Sports Med. 2013;41(10):2333-9.

16. Guermazi A, Niu J, Hayashi D, Roemer FW, Englund M, Neogi $T$, et al. Prevalence of abnormalities in knees detected by MRI in adults without knee osteoarthritis: population based observational study (Framingham Osteoarthritis Study). BMJ. 2012;345:e5339.

17. Sihvonen R, Englund M, Turkiewicz A, Jarvinen TL, Finnish Degenerative Meniscal Lesion Study G. Mechanical Symptoms and Arthroscopic Partial Meniscectomy in Patients With Degenerative Meniscus Tear: A Secondary Analysis of a Randomized Trial. Ann Intern Med. 2016;164:449-55.

18. Roemer FW, Kwoh CK, Hannon MJ, Hunter DJ, Eckstein F, Grago J, et al. Partial meniscectomy is associated with increased risk of incident radiographic osteoarthritis and worsening cartilage damage in the following year. Eur Radiol. 2017;27(1):404-13.

19. Agarwalla A, Gowd AK, Liu JN, Amin NH, Werner BC. Rates and Risk Factors of Revision Arthroscopy or Conversion to Total Knee Arthroplasty Within 1 Year Following Isolated Meniscectomy. Arthrosc Sports Med Rehabil. 2020 Oct 24;2(5):e443-e449.

20. Boyd JA, Gradisar IM. Total knee arthroplasty after knee arthroscopy in patients older than 50 years. Orthopedics. 2016;39:e1041-4.

21. Jameson SS, Rushton SP, Dowen D, Baker P, James P, Reed MR, et al. Increasing age and female gender are associated with early knee replacement following arthroscopy. Knee Surg Sports Traumatol Arthroscopy. 2014;22:2665-71.

22. Peterfy CG, Schneider E, Nevitt M. The osteoarthritis initiative: report on the design rationale for the magnetic resonance imaging protocol for the knee. Osteoarthr Cartil. 2008;16:1433-41.

23. Soellner ST, Goldmann A, Muelheims D, Welsch GH, Pachowsky ML. Intraoperative validation of quantitative T2 mapping in patients with articular cartilage lesions of the knee. Osteoarthr Cartil. 2017;25:1841-9.

24. Eckstein F, Kwoh CK, Boudreau RM,Wang Z, Hannon MJ, Cotofana S, et al. Quantitative MRI measures of cartilage 


\section{CLINICAL ASPECTS}

predict knee replacement: a case-control study from the Osteoarthritis Initiative. Ann Rheum Dis. 2013;72:707-14.

25. Zikria B, Hafezi-Nejad N,Wilckens J, Ficke JR, Demehri S. Determinants of knee replacement in subjects with a history of arthroscopy: data from the osteoarthritis initiative. Eur J Orthop Surg Traumatol. 2016;26:665-70.

26. Dwyer T, Martin CR, Kendra R, Sermer C, Chahal J, Ogilvie-Harris D, et al. Reliability and validity of the arthroscopic International Cartilage Repair Society classification system: correlation with histological assessment of depth. Arthroscopy. 2017;33:1219-24.

27. Klasan A, Putnis SE, Neri T, Leie M, Coolican MR. Patients with lateral compartment knee osteoarthritis during arthroscopy are at highest risk of subsequent knee arthroplasty. The Knee. 2020;27:1476-83.

28. Siemieniuk RAC, Harris IA, Agoritsas T, Poolman RW, Brignardello-Petersen R, de Velde SV, et al. Arthroscopic surgery for degenerative knee arthritis andmeniscal tears: a clinical practice guideline. BMJ. 2017;357:j1982.

29. Katz JN, Jones MH. Treatment of Meniscal Tear: the more we learn, the less we knowtreatment of meniscal tear: the more we learn, the less we know. Ann Intern Med. 2016;164(7):503-4.

30. Moseley JB, O'Malley K, Petersen NJ, Menke TJ, Brody BA, Kuykendall DH, Hollingsworth JC, Ashton CM, Wray NP. A controlled trial of arthroscopic surgery for osteoarthritis of the knee. N Engl J Med. 2002;347(2):81-8.

31. Su X, Li C, Liao W, Liu J, Zhang H, Li J, et al. Comparison of arthroscopic and conservative treatments for knee osteoarthritis: a 5-year retrospective comparative study. Arthroscopy: The Journal of Arthroscopic \& Related Surgery. 2018;34:652-9.

32. Abram SGF, Judge A, Beard DJ, Price AJ. Rates of knee arthroplasty within one-year of undergoing arthroscopic partial meniscectomy in England: temporal trends, regional and age-group variation in conversion rates. Osteoarthr Cartil. 2019;27:1420-9.

33. Steadman JR, Briggs KK, Matheny LM, Ellis HB. Tenyear survivorship after knee arthroscopy in patients with Kellgren-Lawrence grade 3 and grade 4 osteoarthritis of the knee. Arthroscopy: The Journal of Arthroscopic and Related Surgery. 2013;29(2):220-5. 